domiciliary oxygen therapy in chronic hypoxic cor pulmonale complicating chronic bronchitis and emphysema. Lancet $1981 ; \mathrm{i}: 681-5$.

15 Stark RD, Finnegan P, Bishop JM. Long term domiciliary oxygen therapy in chronic bronchitis with pulmonary hypertension. $B M J$ 1973;iii:467-70.

16 Department of Health and Social Security. National Health Service England and Wales: amendments to drug tariff. London: DHSS, 1985. (DTA/IZ.)

17 Bloom BS, Daniel JM, Wiseman M, Knorr RS, Cebul R, Kissick WL. Transtracheal oxygen delivery and patients with chronic obstructive pulmonary disease. Respir Med 1989;83:281-8.
18 Conference report: Further recommendations for prescribing and supplying long term oxygen therapy. Am Rev Respir Dis 1988;138:745-7.

19 Lane R, Cockcroft A, Adams L, Guz A. Arterial oxygen saturation and breathlessness in patients with chronic obstructive airways disease. Clin Sci 1987;72:693-8.

20 Swinburn CR, Wakefield JM, Jones PW. Relationship between ventilation and breathlessness during exercise in chronic obstructive airways disease is not altered by prevention of hypoxaemia. Clin Sci 1984;67:515-9.

21 Lock SH, Blower G, Prynne M, Wedzicha JA. Comparison of liquid and gaseous oxygen for domiciliary portable use. Thorax 1992;47:98-100.

\title{
The early days of lobectomy for bronchiectasis
}

Lobectomy became a feasible procedure in the late 1920 s. At that time the technique consisted in freeing the lobe towards the hilum in the plane of the fissure, applying a snare as near the hilum as possible, tightening it to occlude the vessels and bronchus, lopping off the lobe, and sewing up the stump with multiple sutures before removing the snare. Formal dissection and ligature of vessels and closure of bronchial stump did not become standard practice until well into the 1930 s. The snare technique was often complicated by infection of pleura, and empyema was an almost expected postoperative incident; patients might be in hospital for six or eight weeks after operation. Nevertheless, it was strongly advocated for patients with bronchiectasis limited to one lobe. Bronchiectasis of this sort was then not infrequent; so when I was asked to present a demonstration of bronchiectatic lobes removed at the Brompton Hospital for the meeting of the Association of Physicians in London in $1935 \mathrm{I}$ was able to assemble 100 specimens.

Looking back on this experience, I wonder how far the frequency of these operations was determined by a feeling that if a new and exciting procedure can be done it ought to be done. Certainly there was no possibility at that time of the sort of randomised trial that would be required to find out how much good they did; and it remains difficult to devise acceptable trials of any sort of surgical procedure, or of any procedure that is thought to be helpful to selected patients. I formed the strong opinion that commonsense assessment of whether the patient's symptoms could be related to suppurative changes in the part of the lung it was proposed to remove was the best criterion for recommending surgery. If the expectoration of purulent sputum or haemoptysis as the leading symptom, without generalised wheeze or other indication of changes in undilated bronchi in the rest of the lung, relief of symptoms could be expected; but in the presence of such generalised changes results were likely to be disappointing. The temptation to hope that removal of a bronchiectatic lobe in a wheezy, "catarrhal" child would help was hard for some people to resist. I remember one such child in whom, in 1939 , I resisted this temptation. In 1946, after I returned from war service, she turned up at my clinic minus a lobe but with the same symptoms with which she had presented six years earlier. Someone else had succumbed to the temptation to remove the lobe containing the dilated bronchi. The operation had, of course, been performed by the more refined dissection technique; but the postoperative course had been complicated, leading to bronchiectasis in a previously unaffected part of the lung - and she was still wheezy.

GUY SCADDING 